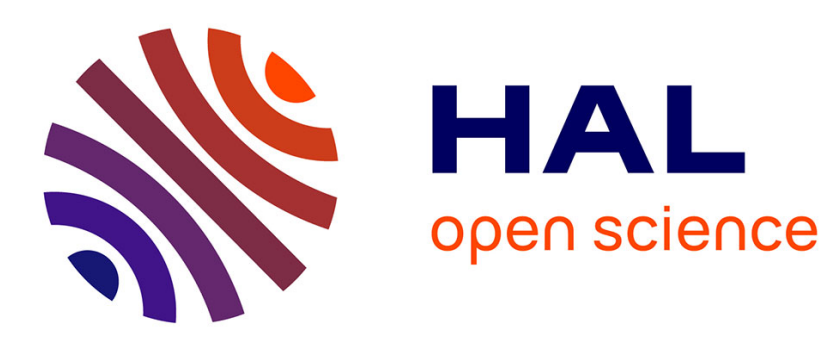

\title{
A simple process for the recovery of palladium from wastes of printed circuit boards
}

Damien Bourgeois, Valentin Lacanau, Régis Mastretta, Christiane

Contino-Pépin, Daniel Meyer

\section{- To cite this version:}

Damien Bourgeois, Valentin Lacanau, Régis Mastretta, Christiane Contino-Pépin, Daniel Meyer. A simple process for the recovery of palladium from wastes of printed circuit boards. Hydrometallurgy, 2020, 191, pp.105241. 10.1016/j.hydromet.2019.105241 . hal-03365417

\section{HAL Id: hal-03365417 \\ https://hal.umontpellier.fr/hal-03365417}

Submitted on 5 Oct 2021

HAL is a multi-disciplinary open access archive for the deposit and dissemination of scientific research documents, whether they are published or not. The documents may come from teaching and research institutions in France or abroad, or from public or private research centers.
L'archive ouverte pluridisciplinaire HAL, est destinée au dépôt et à la diffusion de documents scientifiques de niveau recherche, publiés ou non, émanant des établissements d'enseignement et de recherche français ou étrangers, des laboratoires publics ou privés. 


\section{A simple process for the recovery of palladium from wastes of printed circuit boards}

Damien Bourgeois $^{\mathrm{a}}$, Valentin Lacanau ${ }^{\mathrm{a}, \mathrm{b}}$, Régis Mastretta ${ }^{\mathrm{a}}$, Christiane Contino-Pépin ${ }^{\mathrm{b}}$, Daniel Meyer ${ }^{\mathrm{a}}$

a Institut de Chimie Séparative de Marcoule, ICSM, CEA, CNRS, ENSCM, Univ Montpellier, BP 17171, Marcoule, 30207 Bagnols-sur-Cèze, France.

${ }^{b}$ Equipe Chimie Bioorganique et Systèmes Amphiphiles, Institut des Biomolécules Max Mousseron, UMR 5247, Avignon Université, 84911 Avignon, France.

damien.bourgeois@cea.fr 
1 ABSTRACT: An efficient process for the recovery of palladium from waste printed circuits

2 boards (PCBs) is detailed. Palladium is employed as an electrode material in multi-layer

3 ceramic capacitors (MLCCs). These components can be easily removed from PCBs by de-

4 soldering. As palladium is alloyed with silver, its dissolution is readily achieved using dilute

5 nitric acid. As a result, a solution containing palladium along with base metals, mostly

6 copper and iron, is obtained. This solution is then processed through solvent extraction

7 (SX) with a solvent based on $N, N$-dimethyl, $N, N$-dibutyltetradecylmalonamide (BDMA), a

8 robust extracting molecule previously developed in the frame of the reprocessing of waste

9 nuclear fuel. The volume of effluents generated during the SX sequence is limited: iron

10 scrubbing is operated with a very low aqueous to organic phase volume ratio, no specific

11 metal chelator is required for palladium stripping, and no shift from acidic to basic media is

12 required. Finally, a ca $1 \mathrm{~g} / \mathrm{L} \mathrm{Pd}(\mathrm{II})$ aqueous solution with 99,4\% purity is obtained, from

13 which palladium is directly isolated as dichlorodiammine palladium(II) salt $\left(\mathrm{Pd}\left(\mathrm{NH}_{3}\right)_{2} \mathrm{Cl}_{2}\right)$

14 after precipitation with ammonia. Overall, palladium is quantitatively recovered from the

15 leaching solution, and no palladium was detected in the remaining solid residue. Purity is

16 high, as no contaminating metal could be detected in the final palladium salt. The

17 proposed approach is simple and complementary to existing hydrometallurgical processes

18 dedicated to gold and copper recovery.

20 Keywords:

21 Palladium; e-waste; Solvent extraction; Malonamide 


\section{Introduction}

23 Palladium is a precious metal which is principally employed in autocatalysts. The

24 increasing demand in palladium for this application combined with stable production has

25 recently led to a sharp rise in palladium price as the market remains tight (Cowley, 2019).

Palladium price more than doubled over the last three years, and even, in January 2019, reached that of gold. Since then, palladium price regularly reaches ca. $45 \mathrm{k} € / \mathrm{kg}$ (1600 \$/oz). Palladium market is expected to go further in deficit and production from other secondary resources becomes a key to fulfil palladium needs (Sverdrup and Ragnarsdottir, 2016). Supply from the so-called urban mine appears as a very attractive alternative to traditional mining, especially for Western countries, poorly endowed with natural mineral ores (Sun et al., 2016). Collected waste volume is increasing, and largely unexploited resources are regularly disclosed, such as printed circuits boards (PCBs) contained in end of life vehicles (Xu et al., 2019). Gold represents the principal value fraction of metals contained in waste of electric and electronic equipment (WEEE) (Diaz et al., 2016). Copper and silver represent respectively the highest base-metal and semicopper from WEEE (Cui and Zhang, 2008). This technical solution is well-adapted to the reprocessing of used autocatalysts, as precious metals are supported on an inert alumino- 
necessitates complicated off-gas treatments (Cui and Zhang, 2008; Li et al., 2018). In complement, hydrometallurgical processes have been developed to recover valuable metals from waste PCBs: These are generally soaked in acidic baths to remove unwanted base metals (copper, iron, nickel...), which leaves a solid residue, enriched in gold, further processed through dissolution/isolation sequences (Birloaga and Vegliò, 2018). Very often, the outcome of palladium in these processes is not detailed. Efficient techniques targeting palladium recovery from secondary resources are scarce to our knowledge. Detailed analysis of the proposed approaches reveals the difficulty to design a simple process which enables isolation of pure palladium (Table 1). All approaches rely on poorly selective halide based precious metals leaching agents (chloride or iodide media), and (when operated) the purification of palladium can be tedious. Proposed processes often end up with a mixture, of low or unspecified palladium concentration, and isolation of pure palladium is seldom performed. Finally, some proposed processes clearly raise safety issues (Table 1). As 8 to $9 \%$ of the total palladium demand is employed in electronic goods manufacturing, it is clearly understandable that palladium recycling from waste PCBs deserves a much deeper consideration.

Available data suggest that palladium concentration in waste PCBs ranges between 10 and $100 \mathrm{mg} / \mathrm{kg}$ (Yazici and Deveci, 2013; Zhang and Zhang, 2014). Higher concentrations have been found in specific cases, though on quite old samples (Cui and Zhang, 2008). In PCBs, palladium is principally employed in multi-layer ceramic capacitors (MLCCs) because of its electrical conductivity and its durability (Işıldar et al., 2018; Prabaharan et al., 2016). Palladium is found in the conductive electrode material sandwiched between insulating ceramic layers. Apart from very old MLCCs (more than 20 years old), where $100 \% \mathrm{Pd}$ electrode material was employed, palladium is found in an alloy with silver (Lee, 2010; Wang et al., 1994). A cheaper alternative to the use of silver-palladium alloys is the 
71 use of nickel electrodes, which leads to heavier and less durable MLCCs. As nickel is a

72 ferromagnetic metal, different MLCC classes can be easily discriminated with a simple

73 magnet: Base metal electrodes (BME) MLCCs are magnetic, whereas precious metal 74 electrodes (PME) MLCCs are not. Most of precious metals recovery processes from waste 75 PCBs start with a shredding or grinding step (Table 1). The purpose of this step is to 76 ensure access to the metallic parts for the leaching/dissolving agent, and is directly 77 inspired from the comminution step of natural ores processing. In the case of waste PCBs, accessible (surface layers, continuous contact...) and ii. reducing PCBs into powder also leads to total mixing of the metals. Several studies focusing on gold and copper suggest

81 removing electronic components from boards prior to leaching in order to lower the amount 82 of leaching agent required (Choudhary et al., 2017; Fontana et al., 2018). Components are connected to the boards through solders, mostly made of Sn-Pb based alloys in waste PCBs, which can easily be removed either via thermal or chemical treatment (Kaya, 2018). This simple step enables obtaining electronic components separated from naked boards. The location of palladium in MLCCs pushes towards such an approach, which enables 87 simple separation of palladium and gold/copper flows.

88 In this work, we describe a complete detailed study which enables the recovery of 89 palladium from used PCBs, through a hydrometallurgical process based on chemical de90 soldering of components, including MLCCs, followed by selective leaching with nitric acid, 91 selective palladium extraction with a malonamide (N,N-dimethyl, $N, N$ 92 dibutyltetradecylmalonamide, BDMA, Figure 1) based solvent, and precipitation of a pure 93 palladium salt using standard techniques. The choice of the extracting molecule was 94 motivated by our previous results which demonstrated its excellent performance in the 95 processing of complex aqueous nitrate solutions containing palladium (Mastretta et al., 
2019; Poirot et al., 2016), along with the consequent technical knowledge gathered during process development studies dedicated to spent nuclear fuel reprocessing with same molecule (Modolo et al., 2007). The adaptation of an existing technology for a new application thus only deserves proof of concept at the laboratory scale, as most process issues have already been tackled out. Overall, the proposed process generates a solid residue which contains most initial gold and copper content, and a controlled volume of aqueous effluents, which can be in part reemployed in the leaching step.

\section{Experimental}

\subsection{Materials and reagents}

Used electronic devices were picked up randomly from WEEE collection points and manually dismantled to recover the PCBs contained inside. Concentrated nitric acid, concentrated hydrochloric acid, sodium chloride, toluene and aqueous $28 \%$ ammonia solution were purchased from Carlo Erba reagents. $N, N$-dimethyl, $N, N$ dibutyltetradecylmalonamide (BDMA, Figure 1) was kindly provided by the Commissariat à l'Energie Atomique et aux Energies Alternatives (CEA, France).

\subsection{Dissolution of solders}

A $3 \mathrm{M}$ aqueous nitric acid solution $(200 \mathrm{~mL})$ was placed in a beaker and heated at $50^{\circ} \mathrm{C}$. Entire PCBs were placed in the solution and regularly gently swirled into the solution until components fall to the bottom of the beaker (maximum $15 \mathrm{~min}$ ). The boards were removed, and the components recovered after filtration. The solution became turbid, and a white solid settled in the bottom, and it was isolated after centrifugation. 
$121 \quad 2.3$ Complete digestion of components

122 With aqua regia: Components were weighed and placed in a glass vessel. A mixture of $12332 \% \mathrm{HCl}$ and $69 \% \mathrm{HNO}_{3} 2 / 1(\mathrm{v} / \mathrm{v})$ at a $25 \mathrm{~g} / \mathrm{L}$ solid/liquid ratio $(\mathrm{S} / \mathrm{L}=1 / 40)$ was then 124 added, and the vessel was covered with a glass slip. The resulting mixture was stirred at $12580^{\circ} \mathrm{C}$ for $24 \mathrm{~h}$ using an IKA-Mag magnetic stirrer and a teflon coated bar. The resulting 126 suspension was filtered with a $0.20 \mu \mathrm{m}$ filter and the resulting solution analyzed by 127 ICP/AES. The residual solid was analyzed by SEM.

128 With aqueous nitric acid solution: The same procedure was applied, using a $3 \mathrm{M}$ aqueous $129 \mathrm{HNO}_{3}$ solution.

131 2.4 Palladium leaching from MLCCs

132 Components were weighed and placed in a glass beaker. A $3 \mathrm{M}$ aqueous $\mathrm{HNO}_{3}$ solution at 133 a $100 \mathrm{~g} / \mathrm{L}$ solid/liquid ratio $(\mathrm{S} / \mathrm{L}=1 / 10)$ was then added, and the beaker was covered with 134 a glass slip. The resulting mixture was stirred at $80^{\circ} \mathrm{C}$ for $4 \mathrm{~h}$ using an IKA-Mag magnetic 135 stirrer and a teflon coated bar. The resulting suspension was centrifuged to remove fine 136 particles (ceramics, remaining tin(IV) oxide).

\subsection{Solvent Extraction}

140 Extractions were carried out in $50 \mathrm{~mL}$ glass vials by putting in contact the aqueous solution 141 resulting from leaching of components with an organic phase containing BDMA in toluene. 142 The two phases were vigorously shaken at 1000 vibrations per min with an IKA-Vibrax 143 VXR basic shaker in a $20-22^{\circ} \mathrm{C}$ environment during $1 \mathrm{~h}$. The vials were removed and let to 144 stand for $5 \mathrm{~min}$ and the phases were separated. Scrubbing and stripping stages were 
145 performed in $50 \mathrm{~mL}$ glass vials by putting in contact the organic phase resulting from 146 previous stage, with an adequate aqueous solution (diluted nitric acid solution, pure water 147 of sodium chloride solution, see text). The volume of the aqueous phase was chosen 148 according to the $\mathrm{A} / \mathrm{O}$ ratio detailed in the text. The two phases were vigorously shaken at 1491000 vibrations per min with an IKA-Vibrax VXR basic shaker in a $20-22^{\circ} \mathrm{C}$ environment 150 for $1 \mathrm{~h}$. The vials were removed and let to stand for $5 \mathrm{~min}$ and the phases were separated. 151 When necessary, $500 \mu \mathrm{L}$ of each phase were taken for analysis.

2.6 Palladium precipitation

154 To the aqueous sodium chloride solution containing $\mathrm{Pd}(\mathrm{II})$ was added dropwise an 155 aqueous $28 \%$ ammonia solution until the solution became clear and colorless and the 156 medium became basic (ca. $5 \%$ of the initial volume needed). To the resulting solution, a $1576 \mathrm{M}$ aqueous hydrochloric solution was added dropwise under constant stirring until 158 precipitation of a yellow solid. The resulting suspension was stirred until it cooled to room 159 temperature, and filtered. The resulting solid was washed with water and dried in an oven 160 at $40^{\circ} \mathrm{C}$ overnight.

2.7 Determination of metal concentration in solutions

163 Aliquots of aqueous phases were directly diluted into a $2 \% \mathrm{HNO}_{3}$ aqueous solution. Metals 164 contained in the aliquots of the organic phases were back-extracted with $800 \mu \mathrm{L}$ of an 165 aqueous $0.1 \mathrm{M}$ thiourea solution at $20-22^{\circ} \mathrm{C}$ for $1 \mathrm{~h}$. Both phases were separated, and $166500 \mu \mathrm{L}$ of the resulting aqueous solution were taken and diluted into a $2 \% \mathrm{HNO}_{3}$ aqueous 167 solution. Concentrations of each metal in both aqueous phases (extraction and stripping 168 phases) were determined by inductively coupled plasma atomic emission spectroscopy 169 (ICP/AES, SPECTRO ARCOS ICP Spectrometer, AMETEK Materials Analysis). Given 
170 concentrations are calculated as the means of three replicates on three different 171 wavelengths for each metal; relative standard deviations were determined and lie between 1721 and 4\%. Quantification limits (LoQ) in each analyzed phase were determined for each 173 metal from the dilution factor applied and from the background equivalent concentration 174 (BEC), calculated by the spectrometer for each optical line.

2.8 Powder X-ray diffraction (PXRD)

177 The PXRD pattern of the obtained solid was recorded at ambient temperature on a Bruker

178 D8 ADVANCE powder diffractometer using Ni filtered CuK $_{\alpha 1}(\lambda=1.5406 \AA)$ radiation. Data 179 was collected in the range $5-60^{\circ}(2 \theta)$, with a step of $0.01^{\circ}$, and a scanning rate of $0.1^{\circ} / \mathrm{min}$. 180

1812.9 Scanning Electronic Microscopy (SEM) and elemental analysis

182 SEM characterization was obtained with a FEI QUANTA FEG 200 environmental scanning 183 electron microscope (ESEM) equipped with a gaseous secondary electron detector 184 (GSED). Experiments were performed at $100 \mathrm{~Pa}$ and an accelerating voltage of $15 \mathrm{kV}$. 185 Elemental analysis was performed with X-ray Energy dispersive spectrometry (X-EDS) 186 analyses using a Bruker AXS X-flash 5010 detector coupled to the ESEM.

\section{Results and discussion}

3.1 Chemical de-soldering and isolation of MLCCs

191 Thermal de-soldering of components from PCBs has been implemented at the industrial 192 scale. Its application requires specific equipment and temperature control to enable 193 complete melting without emission of toxic lead fumes. On smaller scale, it may be 
194 interesting to turn to chemical de-soldering (Zhang et al., 2015). Several media have been

195 employed, and the most efficient technique appears to be immersion into an aqueous nitric 196 acid bath (Yang et al., 2011; Yoo et al., 2012). We evaluated at laboratory scale the 197 removal of electronic components from boards after immersion into $3 \mathrm{M}$ aqueous nitric 198 acid solution. Small pieces (ca. $2 \times 2 \mathrm{~cm}^{2}$ ) of different PCBs were cut off and immersed 199 into $3 \mathrm{M}$ nitric acid. According to the board studied, complete dissolution was either 200 observed after a few minutes at room temperature, or after 10 to $15 \mathrm{~min}$ of gentle heating. 201 This behavior may be related to the composition of solders employed and/or the presence 202 of varnish. Altogether, a $3 \mathrm{M}$ aqueous nitric acid bath was prepared and heated at $50^{\circ} \mathrm{C}$ in 203 order to achieve removal of components from all PCBs studied. Most small components 204 fall to the bottom of the bath, while some pinned components remain on the board. 205 Interestingly, MLCCs are not pinned on the boards (Figure 2), and pinned components are 206 generally memory bars or processors, which often contain gold. De-soldered components 207 are then recovered after simple filtration.

208 Chemical de-soldering has several advantages. First of all, it is a safe operation. Only 209 dilute aqueous nitric acid is employed, no brown $\mathrm{NO}_{x}$ fume could be observed. It is a rapid 210 process, as tin, lead and $\mathrm{Sn}-\mathrm{Pb}$ alloys dissolutions are very easy in nitric acid. Secondly, 211 no gold is leached into nitric acid in the absence of chloride ions, and copper is almost not 212 attacked during this process. The de-soldering solution was analyzed (Table 2) and 213 contains $\mathrm{Cu}$ at a $\mathrm{g} / \mathrm{L}$ level, but this does not represent an important quantity considering 214 the large amount of $\mathrm{Cu}$ contained in PCBs. A rough estimate based on an average weight $215 \mathrm{Cu}$ content of $15 \%$ in PCBs suggests that more than $95 \%$ of $\mathrm{Cu}$ remains on the board. 216 Thirdly, tin can be easily recovered in the process. A white precipitate was observed in the 217 filtrate after few minutes, and its isolation followed by X-EDS analysis revealed that it is 218 exclusively composed of Sn. Actually, oxidation of metallic tin by nitric acid has been 
219 described to lead to complete oxidation into Sn(IV) species, which are soluble only in the 220 presence of chloride ions. Otherwise, hydrolysis of the metallic cation occurs, and leads 221 eventually to precipitation of $\mathrm{Sn}(\mathrm{IV})$ oxide (as $\mathrm{SnO}_{2}$ or $\mathrm{H}_{2} \mathrm{SnO}_{3}$ ), as long as concentrated 222 nitric acid is not employed (Yoo et al., 2012). Finally, no Ag nor Pd were detected in the 223 solution, so that it is relatively uncomplicated, and contains only $\mathrm{Cu}, \mathrm{Pb}, \mathrm{Ni}$ and $\mathrm{Fe}$ as 224 major metallic salts (Table 2). Re-use and reprocessing of such solutions have been 225 already successfully investigated by several authors (Lee et al., 2003; Yang et al., 2017). 226 As a consequence, we have not fully optimized this step.

227 Components recovered after filtration are of various natures. It is possible to operate 228 following leaching step on the whole mixture (Figure 2), or to remove magnetic 229 components and/or processors (black components) and plastic parts. It is also possible to 230 isolate large non-magnetic MLCCs to check their integrity and evaluate their Pd content. At 231 laboratory scale, all these steps were performed manually. But physical techniques to 232 operate sorting of WEEEs pieces have been well developed and can easily be envisioned.

\subsection{Location of Pd in waste PCBs and consequences for leaching}

235 Several non-magnetic MLCCs were selected and collected after de-soldering, and analyzed with optical and scanning electronic microscopy (SEM). The multilayer structure is well visible at low magnification with optical microscopy, but the electrode can only be seen thanks to SEM as its thickness is only in order of $1 \mu \mathrm{m}$ (Figure 2). Chemical analysis 239 by X-ray Energy dispersive spectrometry (X-EDS) revealed the presence of both $\mathrm{Ag}$ and $240 \mathrm{Pd}$, in a ratio varying between $4 / 1$ and $2 / 1$ according to the considered sample. Pd was 241 always found along with silver, confirming the use of Ag-Pd alloys. Barium and titanium 242 were the main elements found in the thick layer, in full agreement with the well-described 243 use of $\mathrm{a} \mathrm{BaTiO}_{3}$ ceramic as the dielectric material. Ag was also detected in the connecting 
244 terminations of the MLCCs, pure in most cases, containing a small amount of Pd in some 245 cases (up to $5 \%$ respective to $\mathrm{Ag}$ ). Similar analysis performed on magnetic MLCCs 246 revealed the use of $\mathrm{Ni}$ or $\mathrm{Ni}-\mathrm{Sn}$ based electrodes, with $\mathrm{Ni}$ or $\mathrm{Cu}$ based connecting 247 terminations.

248 In order to evaluate the amount of palladium present in MLCCs, we tried to perform 249 complete digestion with aqua regia of one MLCC reduced to coarse powder after manual 250 grinding in a mortar. Almost no Pd was detected in the leaching solution (4 mg/L). A white 251 solid residue was left, and its analysis by X-EDS revealed the presence of both $\mathrm{Ag}$ and $\mathrm{Pd}$ 252 in the solid, along with Ti from the ceramic. This result is quite surprising since aqua regia 253 is often proposed for complete dissolution of precious metals present in waste PCBs. 254 Previous studies give however contradictory information about the leaching of $\mathrm{Pd}$ and $\mathrm{Ag}$ 255 by aqua regia: Metallic palladium leads to soluble chloro complexes in aqua regia even in 256 the presence of $\mathrm{Ag}$ (Jung et al., 2009; Prabaharan et al., 2016). The reduction of nitric acid 257 into $\mathrm{NH}_{4}{ }^{+}$could lead to the precipitation of stable red $\mathrm{Pd}\left(\mathrm{NH}_{4}\right)_{2} \mathrm{Cl}_{6}$ without the need for 258 stronger oxidizing agent to stabilize the $\mathrm{Pd}(\mathrm{IV})$ in the system. This has been observed in 259 the presence of $\mathrm{Zn}(\mathrm{II})$ or $\mathrm{Ni}(\mathrm{II})$ ions (Park and Fray, 2009). Ni(II) has been quantified in our 260 study (550-1100 mg/L), but no red precipitate was observed. Silver is not soluble in dilute 261 chloride media, but can be solubilized by concentrated aqua regia as $\mathrm{AgCl}_{2}^{-}$, and this has 262 been observed also using a low 2/1 (v/v) ratio of hydrochloric to nitric concentrated acids 263 (Wang et al., 2016). Surface passivation by AgCl has also been described during attack of 264 metallic $\mathrm{Ag}$ alone in aqua regia even at low concentration, using a 1/40 S/L ratio (Park and 265 Fray, 2009). It is thus reasonable to assume that no dissolution of the Ag-Pd alloy 266 occurred, and that Pd dissolution was prevented by the presence of Ag. Two hypotheses 267 can be put forward: the temperature may be too low, as sometimes complete digestion is 268 performed at higher temperature in pressure vessels, or the S/L ratio may be still too high. 
269 We therefore turned to the use of nitric acid alone. Ag is readily soluble in nitric acid and 3 270 to $6 \mathrm{M}$ aqueous nitric acid solutions have been successfully employed for efficient $\mathrm{Ag}$ 271 leaching from metals mixtures (Petter et al., 2014). Dissolution of Pd in the absence of 272 chloride ions may be sluggish, but its oxidation is accelerated through alloying with $\mathrm{Ag}$ 273 (Cole, 1985). Although available literature regarding selective leaching of palladium alloys, 274 especially $\mathrm{Ag}-\mathrm{Pd}$ alloys, is scarce, we were pleased to find that dissolution using $3 \mathrm{M}$ 275 aqueous nitric acid instead of aqua regia led to efficient Pd dissolution, even after only $4 \mathrm{~h}$. 276 Although it is not possible to state whether Pd leaching is complete, no Pd was detected in 277 the remaining solid, and Pd content in the MLCCs studied was determined to be between 2780,5 and $3 \%$ wt (5 to $30 \mathrm{~g} / \mathrm{kg}$ ). Latter value demonstrates that Pd content in MLCCs can be 279 very high, and that focusing a recovery process on MLCCs should enable to recover 280 substantial Pd contained in waste PCBs. Finally, these results demonstrate that the use of 281 aqua regia for the dissolution of complex matrices containing precious metals is not so 282 simple. It would be possible, using a higher temperature or a lower S/L ratio (i.e. a higher 283 volume of liquid), but this approach does not appear as a good process solution.

284 It is conceivable to use the same nitric acid solution to perform first chemical dissolution of 285 solders then leaching of Pd from components. But such a strategy leads to a solution 286 rather diluted in $\mathrm{Pd}$ (3 to $5 \mathrm{mg} / \mathrm{L}$ ). It appears thus judicious to employ a first bath for de287 soldering, regenerate it according to existing techniques, and then to perform leaching of 288 Pd from components with another aqueous solution, of limited volume. It is also possible to 289 select from the mixture of components obtained after de-soldering only non-magnetic 290 MLCCs. Preliminary leaching experiments (not optimized) led to Pd containing solutions of 291 relatively simple composition (Table 2 ). On the other hand, dissolution of magnetic 292 components led to mixtures containing no $\mathrm{Pd}$, but relatively important concentration of $\mathrm{Cu}$, 293 Fe and Ni instead (Table 2). As in both case contaminating metals are the same, and only 
294 their concentrations differ, the selection of specific MLCCs from the components mixture is 295 not necessary. Indeed, leaching of metals from a mixture of components not selected 296 (Figure 2) led to a solution containing ca. $100 \mathrm{mg} / \mathrm{L} \mathrm{Pd}$ along with $\mathrm{Ag}, \mathrm{Cu}, \mathrm{Fe}, \mathrm{Ni}$ and $\mathrm{Pb}$ at 297 higher concentration, and low amount of Sn and Zn (Table 2).

298 3.3 Separation and purification of Pd from a nitric acid solution

299 Palladium recovery from nitrate media resulting from the dissolution of used nuclear fuel in 300 nitric acid has been largely documented (Kolarik and Renard, 2003). However, we recently 301 highlighted that the proposed solutions are not adequate for a mixture containing common 302 base metals such as $\mathrm{Fe}, \mathrm{Cu}, \mathrm{Pb}, \mathrm{Zn}, \mathrm{Ni}$, etc..., and turned to the use of malonamide based 303 solvents (Mastretta et al., 2019). Malonamides make up a family of extracting molecules 304 developed in the frame of the reprocessing of spent nuclear fuel (Musikas, 1988). Although 305 dedicated to the actinide(III)/lanthanide(III) separation in advanced purification process, 306 e.g. DIAMEX (Facchini et al., 2000; Sypula et al., 2012), their affinity for Pd(II) was also 307 evidenced (Poirot et al., 2014). The optimal process in the nuclear fuel cycle is based on $308 N, N$-dimethyl, $N, N$-dioctylhexylethoxymalonamide (OEMA, Figure 1 ), but the previous 309 candidate, BDMA, showed a higher affinity for Pd(II) (Mastretta et al., 2019; Serrano310 Purroy et al., 2005). Latter molecule is also simpler to prepare, as the tetradecyl chain is 311 commercially available. Both molecules are very robust, stable after prolonged contact 312 with concentrated nitric acid, and even resistant to radiolysis (Le Caër et al., 2012). 313 Process studies performed with continuous feeds in mixer-settlers revealed nice phase 314 splitting (Modolo et al., 2007), probably thanks to low viscosity of the solvent (less than $31510 \mathrm{cP}$ ). Benchmarking with commercially available extractants recently demonstrated that 316 malonamides are very well positioned and should be considered for the recovery of 317 palladium from complex mixtures such as those arising from the dissolution of electronic 318 waste (Mastretta et al., 2019). 
319 Regarding the present study, two key points need to be addressed in order to validate the 320 malonamide technology in Pd recovery processes: i. the possibility to generate low amount 321 of effluents during solvent extraction step, and ii. the effective isolation of $\mathrm{Pd}$ from waste 322 PCBs at laboratory scale. Considering the composition of the leaching solution obtained 323 beforehand, we evaluated the impact of each metal separately on the extraction step 324 (Table 3). It is clear that Fe is the impurity of concern, and that $\mathrm{Cu}$ should be also 325 controlled. All other metals have a lower distribution coefficient and/or a lower 326 concentration in aqueous phase, so that their concentration in organic phase is lower, and 327 that scrubbing of both Fe and Cu will guarantee their elimination from organic phase.

328 Suitable Pd distribution coefficients and Pd/Fe selectivity have been achieved using BDMA 329 in toluene (Poirot et al., 2016). Modelling a counter current process based on Pd extraction 330 step, Fe scrubbing step and Pd stripping step, each of one with 6 stages, leads to 331 quantitative Pd recovery (Mastretta et al., 2019). As it is much simpler to operate cross332 current processes at laboratory and pilot scale, we evaluated a cross-current process at 333 the laboratory scale. The key step in the Pd isolation sequence is the Fe scrubbing step, 334 where minimal Pd loss has to be achieved, along with complete Fe scrubbing generating 335 minimum amount of aqueous effluents. One of the interesting features of the malonamide 336 technology is that no extra scrubbing or stripping agent is required: only careful control of 337 the $\mathrm{HNO}_{3}$ concentration in the aqueous phase is required. The distribution coefficients $338\left(\mathrm{D}_{\mathrm{M}}\right)$ of both $\mathrm{Pd}$ and Fe directly depend on aqueous $\mathrm{HNO}_{3}$ concentration, and as long as 339 final aqueous $\mathrm{HNO}_{3}$ concentration is kept above $1,5 \mathrm{M}, \mathrm{Pd}$ distribution coefficient is well 340 above 1, and Pd/Fe selectivity well above 100 (Table 4). This enables quantitative Pd 341 extraction, along with residual $\mathrm{Fe}$, as this metal can be in much higher concentration in the 342 initial aqueous phase than $\mathrm{Pd}$. This residual Fe has to be scrubbed from organic phase to 343 ensure recovery of pure $\mathrm{Pd}$. The concentrations of metals back-extracted from the organic 
344 phase into the aqueous phase depend on distribution coefficients, along with the organic 345 to aqueous (O/A) phase volume ratio, according to equation (1):

$$
[M]_{a q, f}=\frac{[M]_{\text {org,ini }} \cdot O / A}{1+O / A \cdot D_{M}\left(\mathrm{HNO}_{3}\right)}
$$

As a consequence, for a metal with a high distribution coefficient such as Pd, its loss during a scrubbing step will directly depend on $\mathrm{O} / \mathrm{A}$ and $\mathrm{D}_{\mathrm{Pd}}$, following equation (2):

$$
\text { Pd loss }=\frac{[P d]_{a q, f} \cdot V_{a q}}{[P d]_{\text {org }, \text { ini }} \cdot V_{\text {org }}}=\frac{1}{1+O /{ }_{A} \cdot D_{P d}\left(\mathrm{HNO}_{3}\right)} \approx \frac{1}{O / A \cdot D_{P d}\left(\mathrm{HNO}_{3}\right)}
$$

And for a metal with a very low distribution coefficient such as Fe, its scrubbing from organic phase will be almost quantitative, as long as its concentration in aqueous phase does not exceed saturation. Its final concentration in aqueous phase can be approached using equation (3):

$$
[\mathrm{Fe}]_{a q, f}=\frac{[\mathrm{Fe}]_{\text {org,ini }} \cdot \mathrm{O} / \mathrm{A}}{1+\mathrm{O} / \mathrm{A} \cdot \mathrm{D}_{\mathrm{Fe}}\left(\mathrm{HNO}_{3}\right)} \approx[\mathrm{Fe}]_{\text {org,ini }} \cdot \mathrm{O} / \mathrm{A}
$$

From a practical point of view, there is a compromise to find between the O/A ratio and the nitric acid concentration of the aqueous phase employed for scrubbing. A high O/A ratio will enable a low Pd loss, along with low generation of effluents. A low O/A ratio will enable

361 an optimal $\mathrm{Fe}$ scrubbing. A low aqueous $\mathrm{HNO}_{3}$ concentration will enable efficient $\mathrm{Fe}$ scrubbing but will also increase Pd loss. In a first instance, we evaluated both $\mathrm{Fe}$ scrubbing (elimination) and Pd loss after contacting an organic phase loaded with both

364 metals with an aqueous phase at different O/A ratios (Figure 3). Using only water leads to 365 almost quantitative Fe scrubbing, albeit with important $\mathrm{Pd}$ loss (up to $5 \%$ at a O/A ratio of 5). Using 1,5 $\mathrm{M} \mathrm{HNO}_{3}$ leads to lower Pd loss (less than $2 \%$ when O/A ratio exceeds 7 ), but also lower Fe elimination ( 70 to $80 \%$ only). Altogether it appears clearly that at least two 
stages have to be set in place, and different strategies based on sequential two stage scrubbing were evaluated (Figure 4). The best option consists in a first scrubbing with water only, followed by a $1 \mathrm{M}$ aqueous $\mathrm{HNO}_{3}$ scrubbing, both with an O/A ratio of 10 . In these conditions $\mathrm{Pd}$ purity is $96 \%$ with $3 \% \mathrm{Pd}$ loss. These screening results demonstrate that an efficient Fe scrubbing step can be obtained with minimum generation of effluents: the total volume of waste aqueous phase generated represents only $20 \%$ of the volume of the organic phase. The final organic phase containing Pd can then be processed in order to recover Pd as a Pd(II) salt with classical techniques.

\subsection{Impact of chlorides and consequences for Pd recovery}

Evaluation of the behavior of each metal in the solvent extraction step drove us also to evaluate the impact of the presence of chloride ions in the aqueous phase. Sn is poorly soluble in pure nitrate media, as Sn(IV) precipitates as mentioned beforehand. As a consequence it is difficult to evaluate its distribution coefficient with precision as concentration of $\mathrm{Sn}$ in the organic phase after extraction is below quantification limit. On the other hand, similar experiment performed with a $\mathrm{Sn}(\mathrm{IV})$ chloride solution leads to almost quantitative extraction of Sn. The influence of chloride ions was evaluated on 4 key metals ( $\mathrm{Pd}, \mathrm{Ag}, \mathrm{Fe}$ and $\mathrm{Sn}$, Table 5). It is clear that chloride have a negative impact on the process: i. they inhibit the leaching of $\mathrm{Pd}$ (see above) and lead to the precipitation of $\mathrm{Ag}$, ii. they decrease the efficiency of Pd extraction, and the $\mathrm{Pd} / \mathrm{Fe}$ selectivity as $\mathrm{Fe}$ is extracted more easily into organic phase, iii. they increase the solubility of $\mathrm{Sn}$ and the subsequent extraction of $\mathrm{Sn}$ in the organic phase. Altogether, the use of aqua regia is not only poorly suitable for leaching, but also for Pd recovery. Of course other extraction agents could be envisioned (Fontana et al., 2018), but Sn will require deeper studies as it is employed in the extraction of platinum group metals to increase their extraction efficiency: Sn(II) 
393 chloride is a labilizing agent which is easily co-extracted with Pd or Pt in chloride media 394 (Mojski, 1980). Furthermore, the use of a chloride solution to strip Pd from organic phase appears as a very interesting option for malonamides: With low distribution coefficient in the presence of chloride no specific Pd complexing agent will be required to strip Pd, from organic phase. Afterwards, $\mathrm{Pd}(\mathrm{II})$ salts can be easily precipitated from aqueous chloride solutions as $\mathrm{Pd}\left(\mathrm{NH}_{3}\right)_{2} \mathrm{Cl}_{2}$ salt through classical process.

Altogether, the complete sequence is the following: i. chemical de-soldering, ii. Pd leaching 400 from components, iii. Pd isolation through solvent extraction, iv. Pd precipitation as $401 \mathrm{Pd}\left(\mathrm{NH}_{3}\right)_{2} \mathrm{Cl}_{2}$. The two last points are detailed in Figure 5 and Figure 6. A selected solution 402 containing a high amount of $\mathrm{Fe}$ and $\mathrm{Cu}$ (along with other metals $\mathrm{Ag}, \mathrm{Ni}, \mathrm{Pb}, \mathrm{Sn}, \mathrm{Zn}$ and 403 traces $\mathrm{Al}, \mathrm{Ba}, \mathrm{Nd}, \mathrm{Ti}$ and $\mathrm{Y}$, discarded for clarity) was employed and led to an aqueous 404 solution containing $85 \%$ of the initial Pd amount with a $99,4 \%$ purity: traces of Fe were still 405 quantified in this final Pd solution, $\mathrm{Cu}$ was below quantification limit, and other metals were not detected (Figure 6). This aqueous solution was further processed through successive addition of an ammonia solution and hydrochloric acid solution to lead to quantitative 408 precipitation of $\mathrm{Pd}\left(\mathrm{NH}_{3}\right)_{2} \mathrm{Cl}_{2}$ of characteristic yellow color. SEM, X-EDS and powder X-ray 409 diffraction (PXRD) analysis confirmed the structure and the purity of the salt (Figure 5). No 410 residual Fe was detected in the solid.

$412 \quad 3.5$ Regeneration of solvent

413 We chose not to fully back-extract (strip) Pd from the organic phase in order to minimize 414 the volume of aqueous phase employed: $15 \%$ of the Pd remains in the organic phase. 415 Theoretically, a $15 \%$ Pd hold-up in the extraction solvent should lead to a maximum $17 \%$ $416(1-1 / 0,85)$ increase in the Pd loading in the organic phase after re-use of the organic 417 phase for a new solvent-extraction cycle. Such a slight increase in Pd concentration 
418 should not modify distribution coefficient nor extraction yield. Actually, re-use of this 419 solution for a new extraction cycle led to quantitative Pd extraction from same initial 420 aqueous phase. Organic phase $\mathrm{Pd}$ content is higher, and those of Fe and Cu do not vary 421 significantly. Interestingly, no regeneration of the organic phase was required: usually, 422 stripping the metal of interest with a strong chelator requires washing of the organic phase 423 in order to perform a new extraction cycle. In the present case, possible traces of chloride 424 did not alter Pd extraction. No other aqueous effluents are thus generated. Altogether, 425 starting from one volume of aqueous phase, the same volume of organic phase is needed 426 and can be re-employed in successive cycles, and effluents generated account for only $42730 \%$ of the initial volume to be treated.

428 The choice of solvent is the direct consequence of our former studies on such systems 429 (Mastretta et al., 2019; Poirot et al., 2014). Using BDMA in toluene, we were able to tackle 430 key issues related to the development of a solvent extraction process, i.e. low generation 431 of effluents and solvent regeneration. Working on the worst possible case, i.e. a leaching 432 solution of high Fe concentration, we obtained very satisfactory results. Our previous 433 results demonstrate that the use of aromatic diluent is only motivated by the optimization 434 of $\mathrm{Pd} / \mathrm{Fe}$ selectivity (Poirot et al., 2016), and that otherwise Pd distribution coefficient and 435 solubility in the diluent is marginally affected by shift to an aliphatic diluent (Poirot et al., 436 2014). As toluene is volatile, it would be much safer to use a higher boiling point diluent, 437 such as an aromatic cut (e.g. Solvesso 150). Mixed aliphatic-aromatic cuts could also be 438 employed, and it would also be interesting to investigate malonamide in purely aliphatic 439 diluents when physical sorting of the waste guarantees low Fe content in the leachate. Any 440 of these solutions would also definitely limit inhalation exposure to the toluene, a harmful 441 substance. 


\section{Conclusion}

448 Through this study, we demonstrated that efficient Pd recovery from waste PCBs can be

449 performed at laboratory scale via an approach based on successive de-soldering, Pd 450 leaching with dilute nitric acid, solvent extraction then precipitation. This approach takes 451 profit of the quasi-exclusive location of Pd in MLCCs, and the fact that it is alloyed with $\mathrm{Ag}$. 452 It demonstrates that the systematic recourse to shredding and aqua regia is inappropriate 453 for the recovering of $\mathrm{Pd}$, as it will lead to more complex mixtures and leaching difficulties. 454 Furthermore, the process benefits from previous work, e.g. regeneration of de-soldering 455 baths, and complements existing strategies performed at small industrial scale to recover $456 \mathrm{Au}$ and $\mathrm{Cu}$. Usually, when WEEEs are processed through hydrometallurgy, principal target 457 metal is $\mathrm{Au}$, and other precious metals and base metals are eliminated during a 458 preliminary step in order to maximize Au leaching yield (Figure 7). The proposed process 459 generates a final solid residue which contains still all (or almost all) the Au initially present 460 in the product. This solid residue can be processed according to existing techniques, either 461 directly in the Au leaching step, or with classical base metals dissolution (or even through 462 pyrolysis and grinding for smelting processes). The process also enables selective 463 recovery of $\mathrm{Sn}$ as a solid precipitate after dissolution of the solders. We demonstrated that 464 the organic solvent can be re-employed without loss of performance and that the amount 465 of aqueous waste generated is low (ca. $30 \%$ of the initial volume to be treated). We have 466 not explored the possibility to recover Ag from this waste, but this option will be explored in 
467 a near future. $\mathrm{Pd}$ is isolated as a $\mathrm{Pd}(\mathrm{II})$ salt, dichlorodiammine palladium(II) $\mathrm{Pd}\left(\mathrm{NH}_{3}\right)_{2} \mathrm{Cl}_{2}$, 468 with an excellent purity (no other trace metals detected). This salt is a key intermediate in $469 \mathrm{Pd}$ chemistry as its burning at ca. $1000^{\circ} \mathrm{C}$ leads to $\mathrm{Pd}$ sponge, basis for Pd fine chemistry. 470 To our knowledge, this study is the first one to detail each step from waste PCBs to a key 471 Pd intermediate at the laboratory scale, including outcome of by-products and effluents. 472 Considering the forecasted increasing demand in $\mathrm{Pd}$, such a process could be further 473 developed and implemented at small industrial scale, i.e. on 10-100 $\mathrm{kg}$ of waste PCBs. 474 This is the scale at which regional industrial players operate in the sector of precious 475 metals recovery from waste. These are fully complementary to bigger actors that operate 476 pyrometallurgical processes (Cu smelters). Of course further scale-up of the proposed 477 process is conceivable, and operation of the solvent extraction steps with counter-current 478 continuous mixer-settlers will lead to better performances. But the technological 479 investment is higher, and the access to available waste PCBs may be a limit for cost480 effective operation rate. Thus we suggest in a first instance not to start at a large industrial 481 scale. Finally, this work, along with others mentioned in this article, strongly suggest 482 players to seek for alternatives to systematic shredding and complete leaching. This 483 approach, inspired by extraction of metals from natural ores, is not adapted to the 484 management of wastes of high content in several metals, of much lower tonnage and 485 diversity.

\section{Acknowledgements}

489 The authors are grateful to the LaBex ChemiSyst for funding the PhD thesis grant of $\mathrm{V}$. 490 Lacanau (ANR-10-LABX-05-01), and to the Commissariat à l'Energie Atomique et aux 
491 Energies Alternatives (CEA) for financial support of the study.

492 
Table 1: Summary of previously published studies dedicated to palladium recovery from waste PCBs.

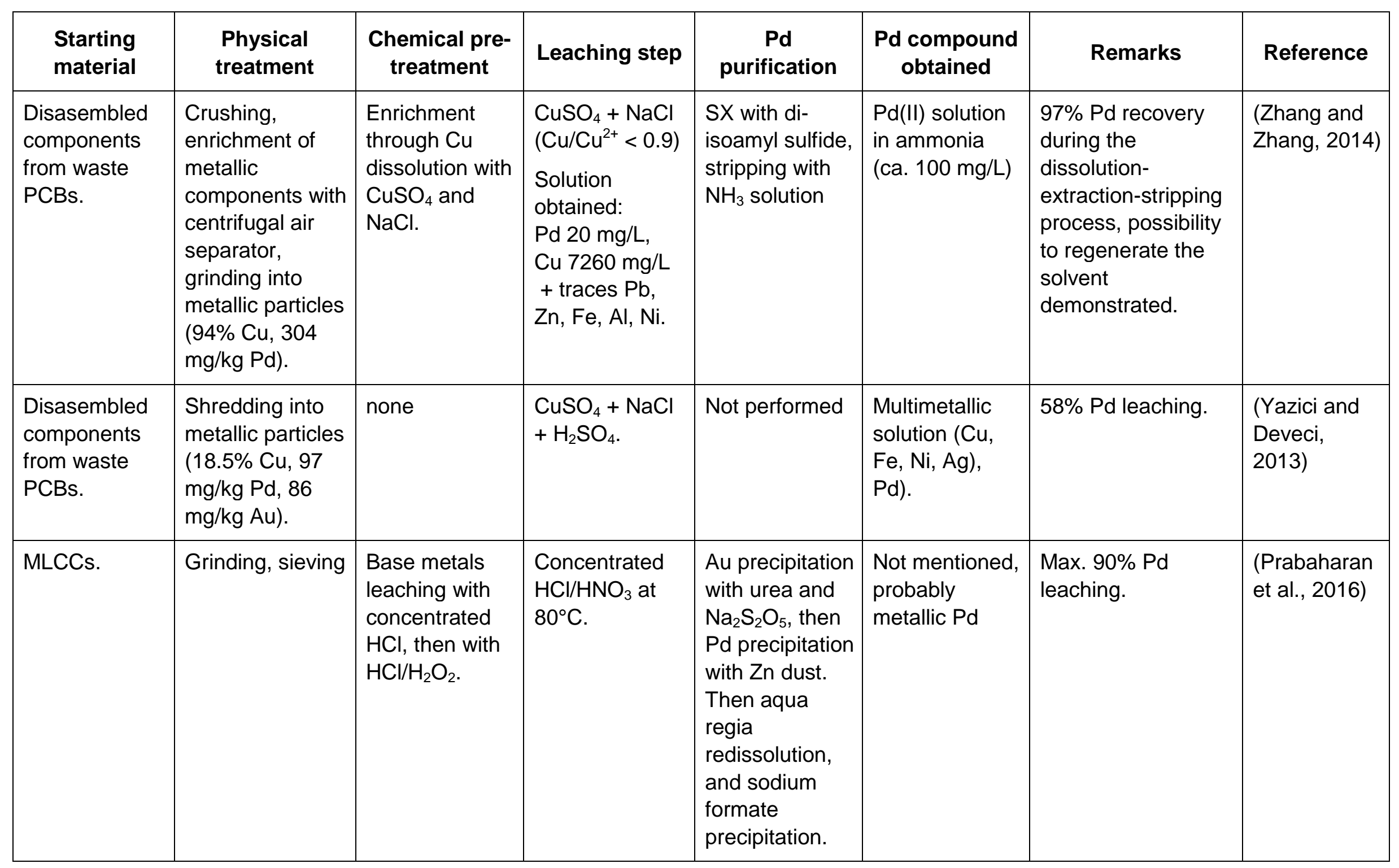




\begin{tabular}{|c|c|c|c|c|c|c|c|}
\hline MLCCs. & Grinding & None & $\begin{array}{l}\text { Concentrated } \\
\mathrm{HCl}^{\prime} \mathrm{HNO}_{3} \text { at } \\
25^{\circ} \mathrm{C} . \\
\text { Solution } \\
\text { obtained: } \\
\mathrm{Pd} 108 \mathrm{mg} / \mathrm{L} \text {, } \\
\mathrm{Cu} 500 \mathrm{mg} / \mathrm{L} \text {, } \\
\mathrm{Fe} 250 \mathrm{mg} / \mathrm{L} \text {, } \\
\mathrm{Pb} 700 \mathrm{mg} / \mathrm{L} \text {, } \\
\mathrm{Mn} 120 \mathrm{mg} / \mathrm{L} \text {, } \\
\mathrm{Ni} 8260 \mathrm{mg} / \mathrm{L} \text {, } \\
\text { Ba } 19 \mathrm{~g} / \mathrm{L}+ \\
\text { traces Ag. }\end{array}$ & $\begin{array}{l}\text { SX with } \\
\text { quaternary } \\
\text { ammonium } \\
\text { chloride } \\
\text { (Aliquat336) in } \\
\text { limonene, then } \\
\text { precipitation } \\
\text { with } \mathrm{NaBH}_{4} \text {. }\end{array}$ & $\begin{array}{l}\text { Precipitate of } \\
\text { metallic Pd and } \\
\mathrm{Ag}, \mathrm{Ba} \text { and } \\
\text { other metals. }\end{array}$ & $\begin{array}{l}\text { Purity depends on } \\
\text { SX efficiency: best } \\
\text { results given } 98.8 \% \\
\text { Pd purity for } 83 \% \\
\text { Pd recovery yield. } \\
\text { Regeneration of } \\
\text { extraction solvent } \\
\text { not evaluated. } \\
\text { The authors } \\
\text { mention the use of } \\
\text { a } 10 \% \text { w/w } \mathrm{NaBH}_{4} \\
\text { solution in water, } \\
\text { but in these } \\
\text { conditions } \mathrm{NaBH}_{4} \\
\text { decomposes with } \\
\text { release of } \mathrm{H}_{2} \text {. }\end{array}$ & $\begin{array}{l}\text { (Fontana et } \\
\text { al., 2018) }\end{array}$ \\
\hline
\end{tabular}




\begin{tabular}{|c|c|c|c|c|c|c|c|}
\hline $\begin{array}{l}\text { 'Blast powder' } \\
\text { (industrial } \\
\text { waste from a } \\
\text { semi- } \\
\text { conductor } \\
\text { processing } \\
\text { unit). }\end{array}$ & None & $\begin{array}{l}\text { None } \\
\text { Composition of } \\
\text { powder: } \\
\text { metallic } \mathrm{Ag} / \mathrm{Pd} \\
\text { alloy, with } \\
\mathrm{Al}_{2} \mathrm{O}_{3} \text {. }\end{array}$ & No leaching & $\begin{array}{l}\text { Liquid-liquid- } \\
\text { powder } \\
\text { extraction with } \\
\text { dodecyl amine } \\
\text { acetate in } \\
\text { kerosene. }\end{array}$ & $\begin{array}{l}\text { Enriched } \\
\mathrm{Pd} / \mathrm{Ag} \text { particles }\end{array}$ & $\begin{array}{l}\text { The technique } \\
\text { focusses on the } \\
\text { physical separation } \\
\text { between } \mathrm{Pd} / \mathrm{Ag} \\
\text { particles and } \mathrm{Al}_{2} \mathrm{O}_{3} \\
\text { particles. }\end{array}$ & $\begin{array}{l}\text { (Ponou et al., } \\
2018 \text { ) }\end{array}$ \\
\hline Waste PCBs. & $\begin{array}{l}\text { Shredding and } \\
\text { crushing. }\end{array}$ & $\begin{array}{l}\text { Supercritical } \\
\text { water } \\
\text { oxidation, then } \\
0.1 \mathrm{M} \mathrm{HCl} \\
\text { leaching of } \\
\text { base metals. }\end{array}$ & $\begin{array}{l}\mathrm{KI}-\mathrm{I}_{2} \text { in acetone } \\
\text { and } \\
\text { supercritical } \\
\mathrm{CO}_{2} \text {. }\end{array}$ & Not performed & $\begin{array}{l}\text { Mixture of } \mathrm{Ag}(\mathrm{I}) \\
\text { and } \mathrm{Pd}(\mathrm{II}) \\
\text { iodides in } \\
\text { partially } \\
\text { iodinated } \\
\text { acetone. }\end{array}$ & $\begin{array}{l}\text { Up to } 94 \% \\
\text { extraction of } \mathrm{Pd} \text {. } \\
\text { Concentration of } \mathrm{Pd} \\
\text { containing solution } \\
\text { not given. }\end{array}$ & $\begin{array}{l}\text { (Liu et al., } \\
2016)\end{array}$ \\
\hline $\begin{array}{l}\text { Waste PCBs } \\
\text { from mobile } \\
\text { phones. }\end{array}$ & $\begin{array}{l}\text { Shredding and } \\
\text { grinding. }\end{array}$ & $\begin{array}{l}\text { Supercritical } \\
\text { water oxidation } \\
\text { using } \mathrm{H}_{2} \mathrm{O}_{2} \text {, } \\
\text { then leaching } \\
\text { of base metals } \\
\text { with diluted } \\
\mathrm{HCl} \text {. }\end{array}$ & $\begin{array}{l}\text { lodine-iodide } \\
\left(\mathrm{KI} / \mathrm{I}_{2} \text { at } \mathrm{pH}=9\right)\end{array}$ & Not performed & $\begin{array}{l}\text { Mixture of } \\
\mathrm{Ag}(\mathrm{I}), \mathrm{Au}(\mathrm{I}) \text { and } \\
\mathrm{Pd}(\mathrm{II}) \text { iodides } \\
\text { in water. }\end{array}$ & $\begin{array}{l}\text { Detailed } \\
\text { optimisation of } \\
\text { process } \\
\text { parameters. } \\
\text { Concentration of Pd } \\
\text { containing solution } \\
\text { not given. }\end{array}$ & $\begin{array}{l}\text { (Xiu et al., } \\
2015)\end{array}$ \\
\hline
\end{tabular}


Table 2: Summary of concentrations $(\mathrm{mg} / \mathrm{L})$ of principal metals of interest found during the dissolution/leaching steps of the process $(\mathrm{Al}, \mathrm{Ba}, \mathrm{Nd}, \mathrm{Ti}$, and $\mathrm{Y}$ were all found below quantification limit and were removed for clarity).

\begin{tabular}{|l|c|c|c|c|c|c|c|c|}
\hline Composition of solution & $\mathbf{A g}$ & $\mathbf{C u}$ & $\mathbf{F e}$ & $\mathbf{N i}$ & $\mathbf{P b}$ & $\mathbf{P d}$ & $\mathbf{S n}$ & $\mathbf{Z n}$ \\
\hline Quantification limit (LoQ) & 0,2 & 0,1 & 0,2 & 0,15 & 0,2 & 0,3 & 0,2 & 0,25 \\
\hline Bath after dissolution of solders & $<\mathrm{LOQ}$ & 1400 & 70 & 180 & 730 & $<\mathrm{LoQ}$ & 40 & $<\mathrm{LOQ}$ \\
\hline $\begin{array}{l}\text { After leaching of selected non- } \\
\text { magnetic MLCC }\end{array}$ & $\begin{array}{c}205- \\
968\end{array}$ & $0-4$ & $0-135$ & $5-41$ & $\begin{array}{c}59- \\
300\end{array}$ & $\begin{array}{c}38- \\
193\end{array}$ & $2-24$ & $<$ LoQ \\
\hline $\begin{array}{l}\text { After dissolution of selected } \\
\text { magnetic components }\end{array}$ & 1 & 2500 & 2650 & 3500 & 700 & $<$ LoQ & 5 & $<$ LoQ \\
\hline $\begin{array}{l}\text { After leaching of components } \\
\text { recovered after dissolution of } \\
\text { solders }\end{array}$ & 481 & 1940 & 970 & 350 & 172 & 98 & 33 & 37 \\
\hline
\end{tabular}


Table 3: Distribution coefficients and maximum concentrations expected in organic phase after solvent extraction for unwanted metals present in leaching solution, of which $\mathrm{HNO}_{3}$ concentration is $3 \mathrm{M}$.

\begin{tabular}{|l|c|c|}
\hline Metal & $\begin{array}{l}\text { Distribution } \\
\text { coefficient (D) }\end{array}$ & $\begin{array}{l}\text { Maximum organic } \\
\text { concentration } \\
\text { (mg/L) }\end{array}$ \\
\hline $\mathrm{Ag}$ & 0,04 & 7 \\
\hline $\mathrm{Cu}$ & 0,015 & 32 \\
\hline $\mathrm{Fe}$ & 0,24 & 88 \\
\hline $\mathrm{Ni}$ & 0,01 & 2 \\
\hline $\mathrm{Pb}$ & 0,02 & 12 \\
\hline $\mathrm{Sn}$ & $(0,04)^{\mathrm{a}}$ & $<$ LoQ \\
\hline $\mathrm{Zn}$ & 0,03 & 1 \\
\hline
\end{tabular}

Note: a. Solubility of tin is very limited in pure nitrate media 
Table 4: Distribution coefficients of Pd and Fe between a 0,6 M BDMA in toluene organic phase and aqueous phases of variable $\mathrm{HNO}_{3}$ concentrations, and corresponding $\mathrm{Pd} / \mathrm{Fe}$ selectivity.

\begin{tabular}{|l|c|c|c|c|c|}
\hline Aqueous $\left[\mathrm{HNO}_{3}\right]$ & $1 \mathrm{~mol} / \mathrm{L}$ & $1,2 \mathrm{~mol} / \mathrm{L}$ & $1,5 \mathrm{~mol} / \mathrm{L}$ & $2 \mathrm{~mol} / \mathrm{L}$ & $3 \mathrm{~mol} / \mathrm{L}$ \\
\hline $\mathbf{D}(\mathbf{P d})$ & 1,7 & 2,5 & 3,7 & 6,1 & 27 \\
\hline $\mathbf{D}(\mathrm{Fe})$ & $<\mathrm{LoQ}^{\mathrm{a}}$ & 0,001 & 0,003 & 0,024 & 0,24 \\
\hline $\mathbf{S}_{\text {Pd/Fe }}$ & n.a. & 2500 & 1230 & 250 & 110 \\
\hline
\end{tabular}

Notes: a. $L o Q=0,001$ in the determination of Fe distribution coefficient. 
Table 5: Impact of the presence of chloride anions on the distribution coefficients of key metals present in leaching solution. Conditions: a controlled quantity of $\mathrm{NaCl}$ was added to a $3 \mathrm{M}$ aqueous $\mathrm{HNO}_{3}$ phase containing dissolved ions.

\begin{tabular}{|l|c|c|c|c|}
\hline Conditions & $\mathbf{D}(\mathbf{P d})$ & $\mathbf{D}(\mathbf{F e})$ & $\mathbf{D}(\mathbf{A g})$ & $\mathbf{D}(\mathbf{S n})$ \\
\hline No chloride & 27 & 0,24 & 0,04 & $(0,04)^{\mathrm{a}}$ \\
\hline 1 M chloride & 0,06 & 1,0 & n.a. $^{\mathrm{b}}$ & 11,2 \\
\hline
\end{tabular}

Notes: a. Solubility of tin is very limited in pure nitrate media; b. precipitation of silver chloride. 
Figure 1: Malonamide extractants: BDMA (also referred to as DMDBTDMA), employed in the study, and OEMA (also referred to as DMDOHEMA), employed in actinide(III)/lanthanide(III) separation.<smiles>CCCCCC(C(=O)N(C)C)C(=O)N(C)C</smiles>

BDMA<smiles>CCN(C)C(=O)C(CCOC)C(=O)N(C)CCO</smiles>

OEMA 
Figure 2: Details of printed circuit boards (PCBs) employed in the study, and location of palladium in multi-layer ceramic capacitors (MLCC) with electron microscope imaging of a MLCC transversal cut. Pictures of leaching step of the process and solids and solution obtained.

Waste printed circuit boards

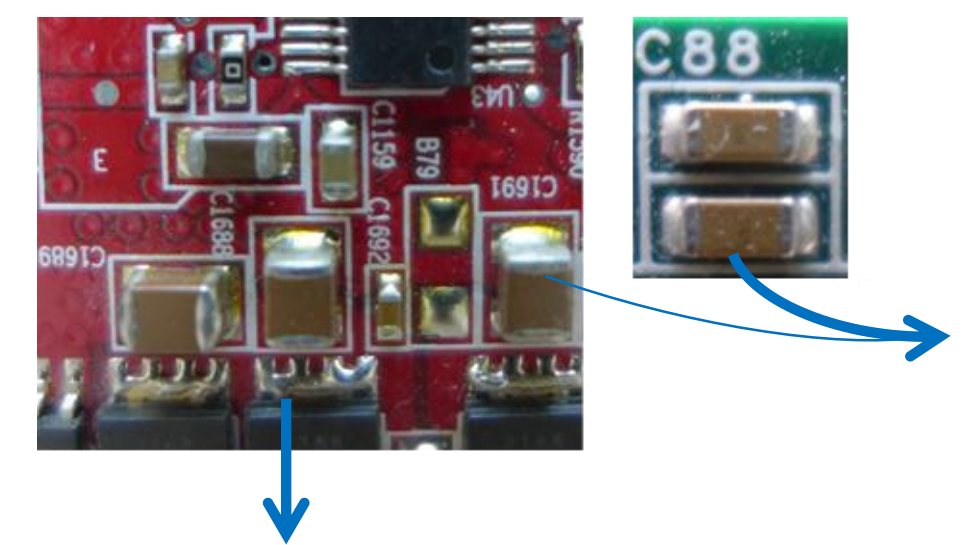

Dissolution of solders \& Recovery of components by filtration

\section{MLCCs}

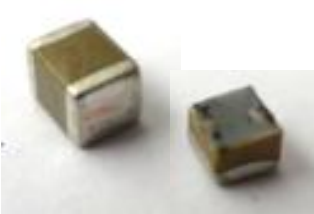

$20 \mu \mathrm{m}$

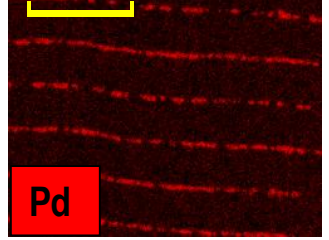

$\checkmark$

Dissolution of components

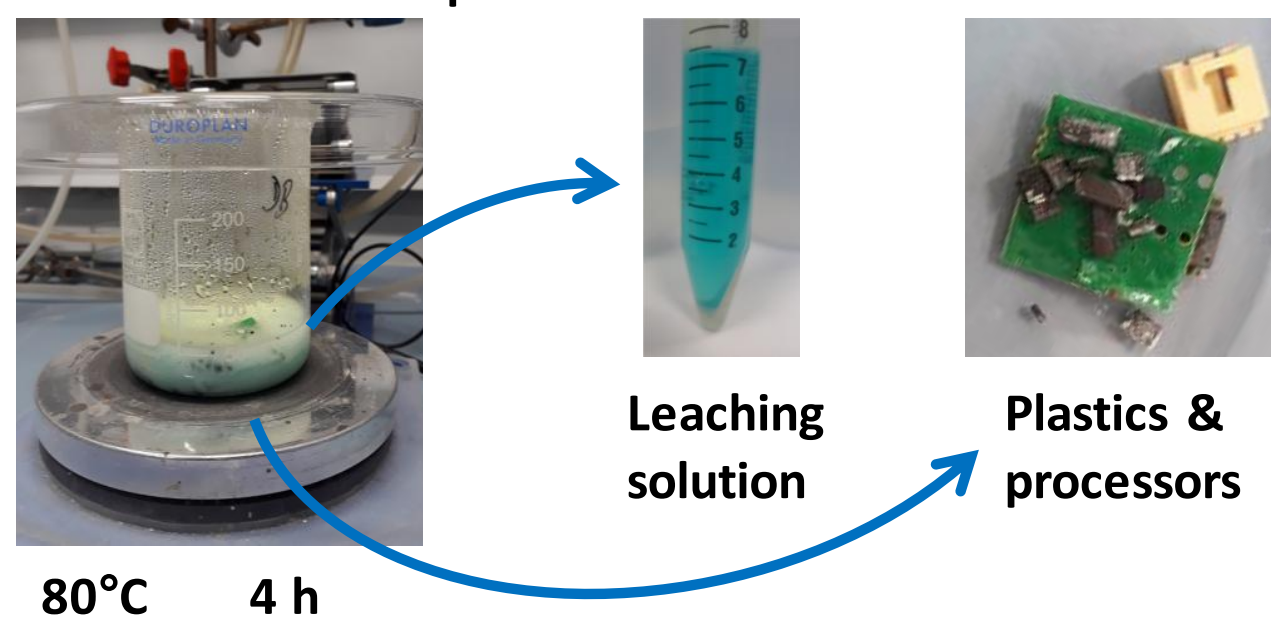


Figure 3: Results of iron elimination and palladium loss during scrubbing. Initial organic phase based on 0,6 M BDMA in toluene, containing $\mathrm{Pd}(196 \mathrm{mg} / \mathrm{L})$ and $\mathrm{Fe}(97 \mathrm{mg} / \mathrm{L})$, scrubbed with different aqueous solutions $\left(\mathrm{H}_{2} \mathrm{O}\right.$ or $\left.1,5 \mathrm{M} \mathrm{HNO}_{3}\right)$ at different organic to aqueous phase volume ratios $(\mathrm{O} / \mathrm{A})$.

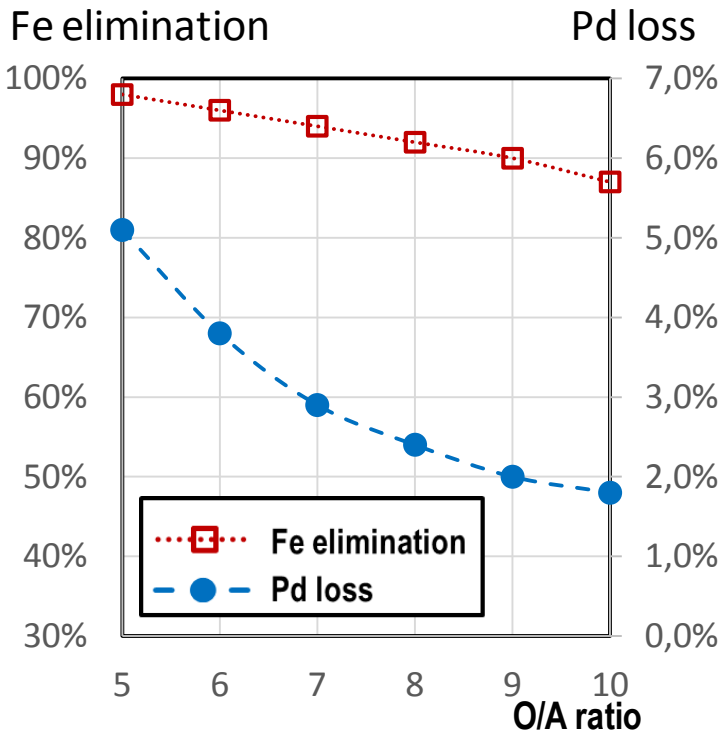

$\mathrm{H}_{2} \mathrm{O}$ scrubbing
Fe elimination Pd loss

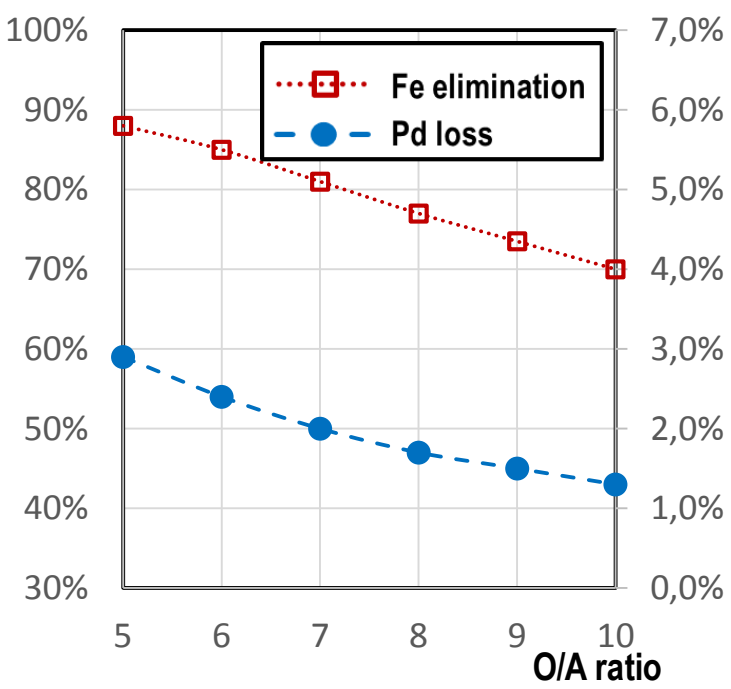

1,5 $\mathrm{M} \mathrm{HNO}_{3}$ scrubbing 
Figure 4: Detailed results of the scrubbing sequence optimization. Initial organic phase: 0,6 M BDMA in toluene, containing Pd (95 mg/L) and Fe (79 mg/L), scrubbed with different aqueous solutions $\left(\mathrm{H}_{2} \mathrm{O}\right.$ or $\left.1 \mathrm{M} \mathrm{HNO}_{3}\right)$ at different organic to aqueous phase volume ratios (O/A). Two scrubbing stages were performed, at same O/A ratio but with possibly different solutions.

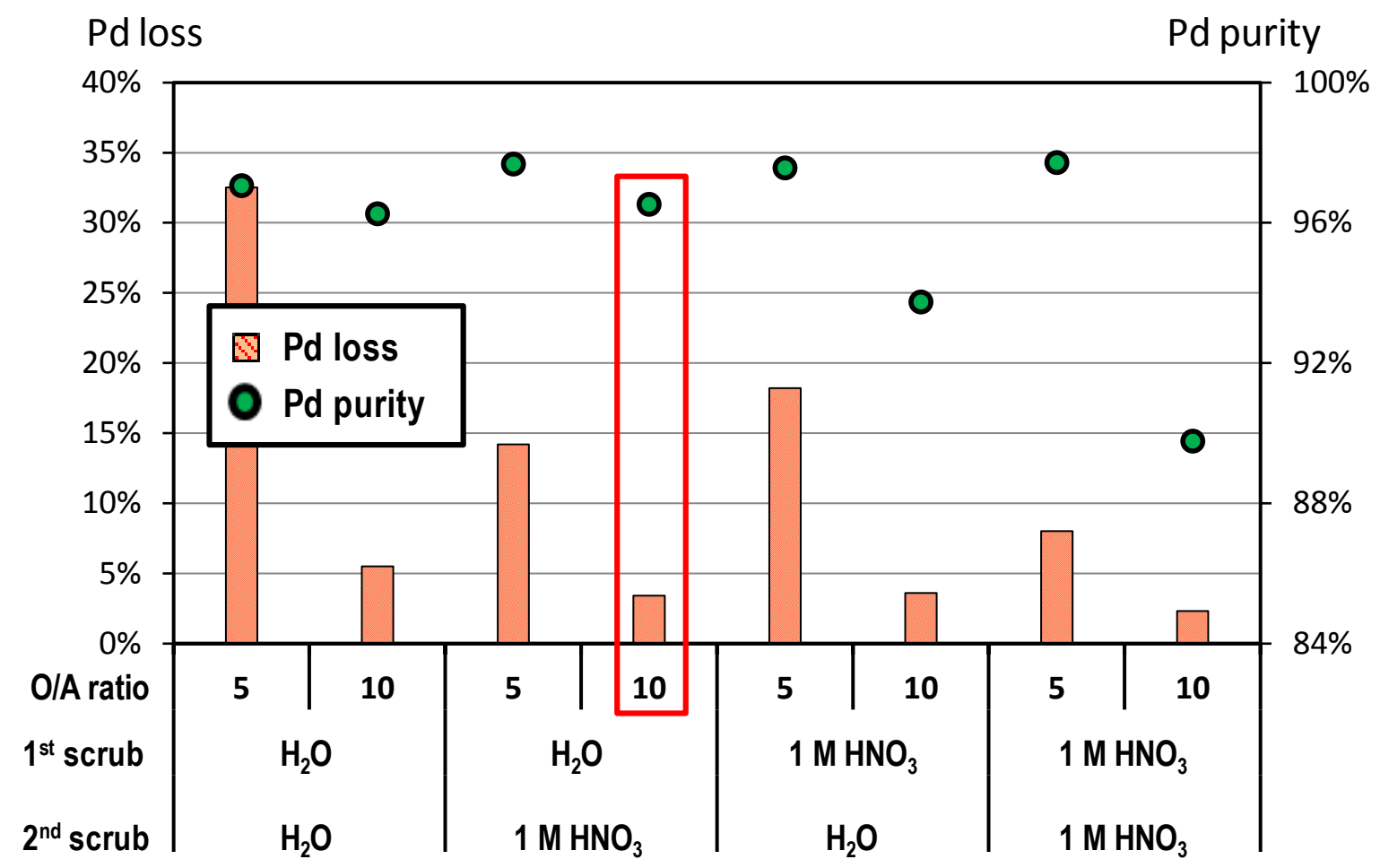


Figure 5: Flowsheet of the palladium recovery section of the process, along with obtained $\mathrm{Pd}$ (II) salt analysis (electron-dispersion analysis and powder X-ray diffractogram). $\mathrm{N}=$ number of stages; $\mathrm{A} / \mathrm{O}=$ aqueous to organic feed ratio; $\mathrm{O} / \mathrm{A}=$ organic to aqueous feed ratio.

\section{Palladium recovery section}

Solvent re-use

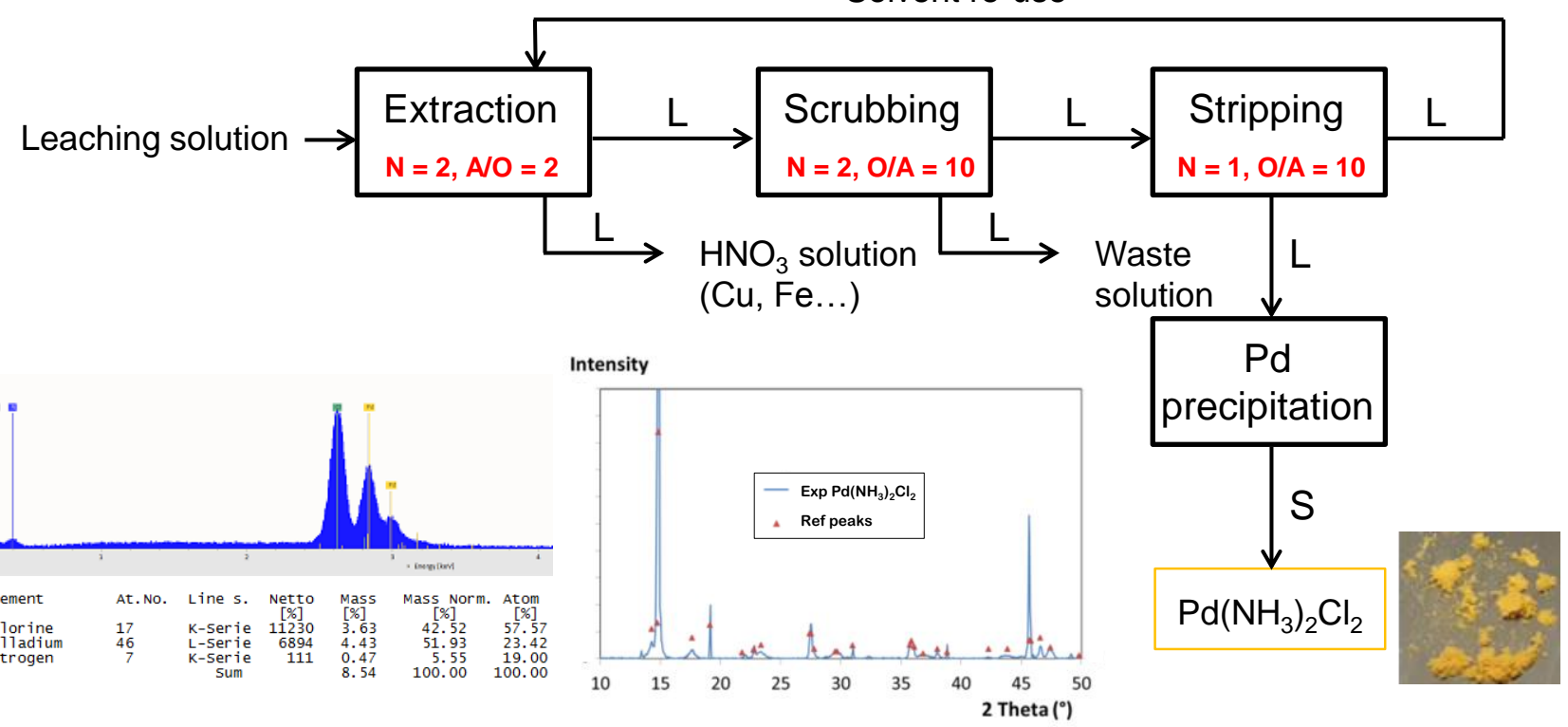


Figure 6: Detailed results of the solvent-extraction processing section of the palladium recovery process (data for other metals not shown for clarity).

\section{INITIAL AQUEOUS FEED}

$$
\begin{aligned}
& \text { Aq. phase content } \\
& \text { Pd } \quad 98 \mathrm{mg} / \mathrm{L} \\
& \text { Fe } \quad 972 \mathrm{mg} / \mathrm{L} \\
& \mathrm{Cu} \quad 1942 \mathrm{mg} / \mathrm{L}
\end{aligned}
$$

\begin{tabular}{|c|c|c|c|c|c|}
\hline \multicolumn{2}{|c|}{ Aq. phase content } & \multicolumn{2}{|c|}{ Org. phase content } & \multicolumn{2}{|c|}{ Extraction yield } \\
\hline $\mathrm{Pd}$ & $<$ LoQ & Pd & 102 mg/L & $\mathrm{Pd}$ & $>99 \%$ \\
\hline $\mathrm{Fe}$ & $795 \mathrm{mg} / \mathrm{L}$ & $\mathrm{Fe}$ & $184 \mathrm{mg} / \mathrm{L}$ & $\mathrm{Fe}$ & $19 \%$ \\
\hline $\mathrm{Cu}$ & $1916 \mathrm{mg} / \mathrm{L}$ & $\mathrm{Cu}$ & $27 \mathrm{mg} / \mathrm{L}$ & $\mathrm{Cu}$ & $1,4 \%$ \\
\hline
\end{tabular}

\begin{tabular}{|c|c|c|c|c|c|}
\hline \multicolumn{2}{|c|}{ Aq. phase content } & \multicolumn{2}{|c|}{ Org. phase content } & \multicolumn{2}{|c|}{ Loss/Extraction yield } \\
\hline $\mathrm{Pd}$ & $16 \mathrm{mg} / \mathrm{L}$ & $\mathbf{P d}$ & $101 \mathrm{mg} / \mathrm{L}$ & $\mathrm{Pd}$ & $1 \%$ \\
\hline $\mathrm{Fe}$ & $1644 \mathrm{mg} / \mathrm{L}$ & $\mathrm{Fe}$ & $20 \mathrm{mg} / \mathrm{L}$ & $\mathrm{Fe}$ & $89 \%$ \\
\hline $\mathrm{Cu}$ & $250 \mathrm{mg} / \mathrm{L}$ & $\mathrm{Cu}$ & $2 \mathrm{mg} / \mathrm{L}$ & $\mathrm{Cu}$ & $93 \%$ \\
\hline
\end{tabular}

Pd EXTRACTION: 2 stages, cross-current, A/O = 2

Fe (and $\mathrm{Cu}$ ) SCRUBBING $\mathrm{H}_{2} \mathrm{O}: \mathrm{O} / \mathrm{A}=10$

Fe SCRUBBING $1 \mathrm{M} \mathrm{HNO}_{3}:$ O/A = 10

\begin{tabular}{lrlrlr}
\multicolumn{2}{l}{ Aq. phase content } & \multicolumn{2}{l}{ Org. phase content } & \multicolumn{2}{l}{ Loss/Extraction yield } \\
$\mathrm{Pd}$ & $30 \mathrm{mg} / \mathrm{L}$ & $\mathrm{Pd}$ & $\mathbf{9 9} \mathrm{mg} / \mathrm{L}$ & $\mathrm{Pd}$ & $4 \%$ \\
$\mathrm{Fe}$ & $168 \mathrm{mg} / \mathrm{L}$ & $\mathrm{Fe}$ & $\mathbf{3 ~ m g / L}$ & $\mathrm{Fe}$ & $98 \%$ \\
$\mathrm{Cu}$ & $5 \mathrm{mg} / \mathrm{L}$ & $\mathrm{Cu}$ & $<\mathrm{LoQ}$ & $\mathrm{Cu}$ & $>99 \%$
\end{tabular}

\begin{tabular}{|c|c|c|c|c|c|}
\hline \multicolumn{2}{|c|}{ Aq. phase content } & \multicolumn{2}{|c|}{ Org. phase content } & \multicolumn{2}{|c|}{ Extraction yiel } \\
\hline $\mathrm{Pd}$ & $<$ LoQ & Pd & 116 mg/L & $\mathrm{Pd}$ & $>99 \%$ \\
\hline $\mathrm{Fe}$ & $753 \mathrm{mg} / \mathrm{L}$ & $\mathrm{Fe}$ & $222 \mathrm{mg} / \mathrm{L}$ & $\mathrm{Fe}$ & $23 \%$ \\
\hline $\mathrm{Cu}$ & 1922 mg/L & $\mathrm{Cu}$ & $23 \mathrm{mg} / \mathrm{L}$ & $\mathrm{Cu}$ & $1,2 \%$ \\
\hline
\end{tabular}

Pd STRIPPING 0,5 M NaCl: O/A = 10

\begin{tabular}{lrlrll} 
Aq. & phase content & \multicolumn{2}{c}{ Org. phase content } & \multicolumn{2}{c}{ Stripping yield } \\
Pd & $\mathbf{8 5 4} \mathrm{mg} / \mathrm{L}$ & $\mathrm{Pd}$ & $14 \mathrm{mg} / \mathrm{L}$ & $\mathrm{Pd}$ & $85 \%$ \\
$\mathrm{Fe}$ & $\mathbf{5 ~ m g / L}$ & $\mathrm{Fe}$ & $2 \mathrm{mg} / \mathrm{L}$ & & \\
$\mathrm{Cu}$ & $<$ LoQ & $\mathrm{Cu}$ & $<\mathrm{LoQ}$ & Pd purity & $\mathbf{9 9 , 4 \%}$
\end{tabular}

NEW EXTRACTION CYCLE: 2 stages, cross-current, A/O = 2 
Figure 7: Comparison between existing processes and proposed process: the proposed process dedicated to $\mathrm{Pd}$ recovery can fit into existing processes with recycling of $\mathrm{Au}$ containing solid waste.

\section{Existing hydrometallurgical process}

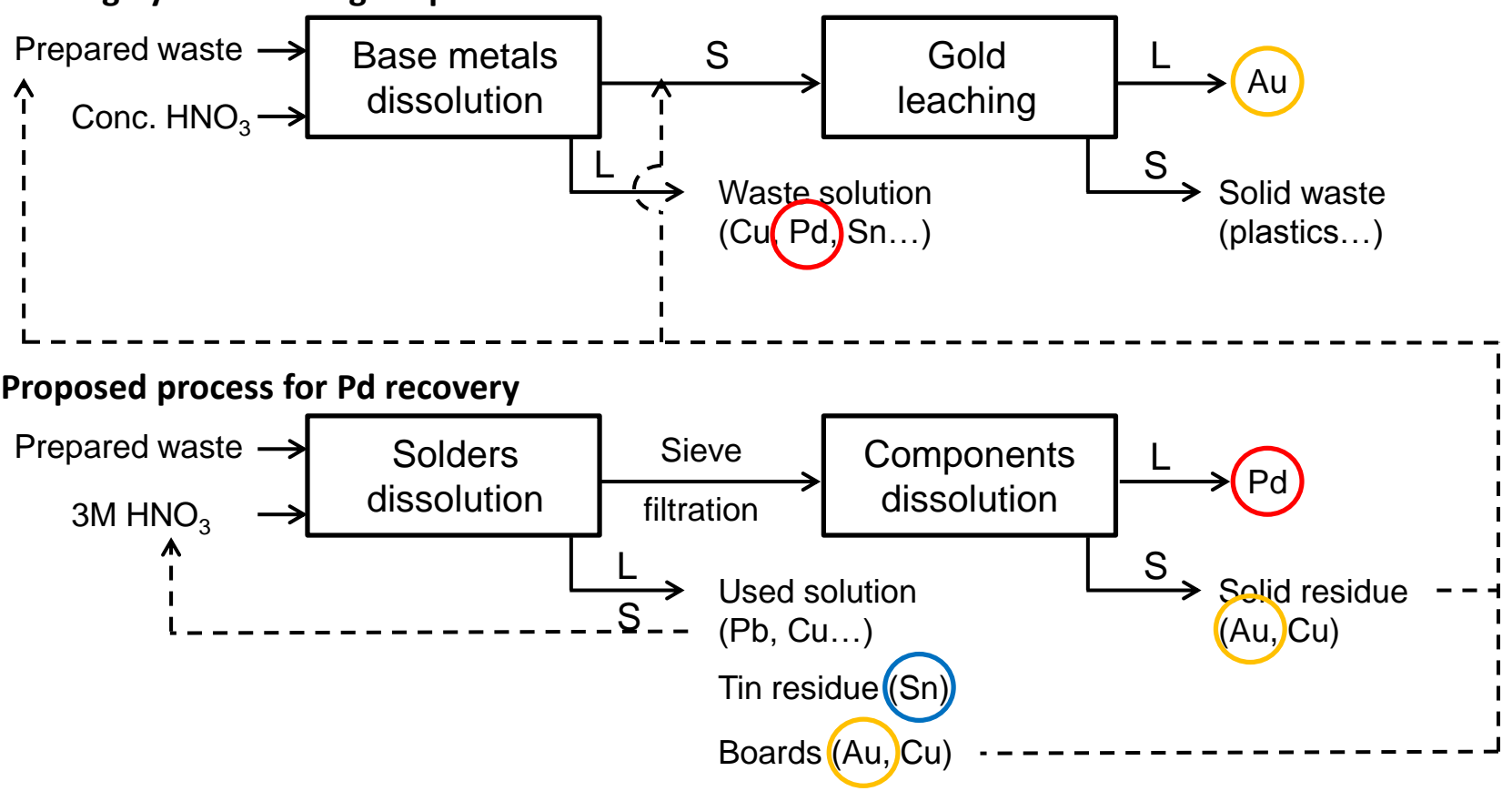




\section{REFERENCES}

Behnamfard, A., Salarirad, M.M., Veglio, F., 2013. Process development for recovery of copper and precious metals from waste printed circuit boards with emphasize on palladium and gold leaching and precipitation. Waste Manag. 33, 2354-2363. https://doi.org/10.1016/j.wasman.2013.07.017

Birloaga, I., Vegliò, F., 2018. Hydrometallurgical processing of waste printed circuit boards, in: Waste Electrical and Electronic Equipment Recycling. Elsevier, pp. 95-113. https://doi.org/10.1016/B978-0-08-102057-9.00004-4

Choudhary, B.C., Paul, D., Borse, A.U., Garole, D.J., 2017. Recovery of palladium from secondary waste using soluble tannins cross-linked Lagerstroemia speciosa leaves powder: Recovery of palladium from secondary waste using biomass. J. Chem. Technol. Biotechnol. 92, 16671677. https://doi.org/10.1002/jctb.5163

Cole, S.S., 1985. Oxidation and Reduction of Palladium in the Presence of Silver. J. Am. Ceram. Soc. 68, C-106-C-107. https://doi.org/10.1111/j.1151-2916.1985.tb15309.x

Cowley, A., 2019. Johnson Matthey Pgm Market Report February 2019.

Cui, J., Zhang, L., 2008. Metallurgical recovery of metals from electronic waste: A review. J. Hazard. Mater. 158, 228-256. https://doi.org/10.1016/j.jhazmat.2008.02.001

Diaz, L.A., Lister, T.E., Parkman, J.A., Clark, G.G., 2016. Comprehensive process for the recovery of value and critical materials from electronic waste. J. Clean. Prod. 125, 236-244. https://doi.org/10.1016/j.jclepro.2016.03.061

Ding, Y., Zhang, S., Liu, B., Zheng, H., Chang, C., Ekberg, C., 2019. Recovery of precious metals from electronic waste and spent catalysts: A review. Resour. Conserv. Recycl. 141, 284298. https://doi.org/10.1016/j.resconrec.2018.10.041

Facchini, A., Amato, L., Modolo, G., Nannicini, R., Madic, C., Baron, P., 2000. Transient- and Steady-State Concentration Profiles in a DIAMEX-like Countercurrent Process for An(III) + Ln(III) Separation. Sep. Sci. Technol. 35, 1055-1068. https://doi.org/10.1081/SS-100100210

Fontana, D., Pietrantonio, M., Pucciarmati, S., Torelli, G.N., Bonomi, C., Masi, F., 2018. Palladium recovery from monolithic ceramic capacitors by leaching, solvent extraction and reduction. J. Mater. Cycles Waste Manag. 20, 1199-1206. https://doi.org/10.1007/s10163-017-0684-3

Hsu, E., Barmak, K., West, A.C., Park, A.-H.A., 2019. Advancements in the treatment and processing of electronic waste with sustainability: a review of metal extraction and recovery technologies. Green Chem. 21, 919-936. https://doi.org/10.1039/C8GC03688H

Iş1ldar, A., Rene, E.R., van Hullebusch, E.D., Lens, P.N.L., 2018. Electronic waste as a secondary source of critical metals: Management and recovery technologies. Resour. Conserv. Recycl. 135, 296-312. https://doi.org/10.1016/j.resconrec.2017.07.031

Jung, B.H., Park, Y.Y., An, J.W., Kim, S.J., Tran, T., Kim, M.J., 2009. Processing of high purity gold from scraps using diethylene glycol di-N-butyl ether (dibutyl carbitol). Hydrometallurgy 95, 262-266. https://doi.org/10.1016/j.hydromet.2008.06.006

Kaya, M., 2018. Current WEEE recycling solutions, in: Waste Electrical and Electronic Equipment Recycling. Elsevier, pp. 33-93. https://doi.org/10.1016/B978-0-08-102057-9.00003-2

Kolarik, Z., Renard, E.V., 2003. Recovery of value fission platinoids from spent nuclear fuel - Part II: Separation processes. Platin. Met. Rev. 47, 123-131.

Le Caër, S., Vigneron, G., Guillaumont, D., Berthon, L., Zorz, N., Moisy, P., 2012. Experimental and theoretical study of the degradation of malonamide extractant molecules under ionizing radiation. RSC Adv. 2, 3954. https://doi.org/10.1039/c2ra01201d

Lee, M.-S., Ahn, J.-G., Ahn, J.-W., 2003. Recovery of copper, tin and lead from the spent nitric etching solutions of printed circuit board and regeneration of the etching solution. Hydrometallurgy 70, 23-29. https://doi.org/10.1016/S0304-386X(03)00045-8 
Lee, Y.-C., 2010. Dielectric Properties and Reliability of $\mathrm{Zn}_{0.95} \mathrm{Mg}_{0.05} \mathrm{TiO}_{3}+0.25 \mathrm{TiO}_{2} \mathrm{MLCCs}$ with Different $\mathrm{Pd} / \mathrm{Ag}$ Ratios of Electrodes. Int. J. Appl. Ceram. Technol. 7, 71-80. https://doi.org/10.1111/j.1744-7402.2008.02327.x

Li, H., Eksteen, J., Oraby, E., 2018. Hydrometallurgical recovery of metals from waste printed circuit boards (WPCBs): Current status and perspectives - A review. Resour. Conserv. Recycl. 139, 122-139. https://doi.org/10.1016/j.resconrec.2018.08.007

Liu, K., Zhang, Z., Zhang, F.-S., 2016. Direct extraction of palladium and silver from waste printed circuit boards powder by supercritical fluids oxidation-extraction process. J. Hazard. Mater. 318, 216-223. https://doi.org/10.1016/j.jhazmat.2016.07.005

$\mathrm{Lu}, \mathrm{Y} ., \mathrm{Xu}, \mathrm{Z} ., 2016$. Precious metals recovery from waste printed circuit boards: A review for current status and perspective. Resour. Conserv. Recycl. 113, 28-39. https://doi.org/10.1016/j.resconrec.2016.05.007

Mastretta, R., Poirot, R., Bourgeois, D., Meyer, D., 2019. Palladium Isolation and Purification from Nitrate Media: Efficient Process Based on Malonamides. Solvent Extr. Ion Exch. 37, 140 156. https://doi.org/10.1080/07366299.2019.1630073

Modolo, G., Vijgen, H., Serrano- Purroy, D., Christiansen, B., Malmbeck, R., Sorel, C., Baron, P., 2007. DIAMEX Counter- Current Extraction Process for Recovery of Trivalent Actinides from Simulated High Active Concentrate. Sep. Sci. Technol. 42, 439-452. https://doi.org/10.1080/01496390601120763

Mojski, M., 1980. Extraction of platinum metals from hydrochloric acid medium with triphenylphosphine solution in 1,2-dichloroethane. Talanta 27, 7-10. https://doi.org/10.1016/0039-9140(80)80003-8

Musikas, C., 1988. Potentiality of Nonorganophosphorus Extractant in Chemical Separations of Actinides. Sep. Sci. Technol. 23, 1211-1226. https://doi.org/10.1080/01496398808075626

Park, Y.J., Fray, D.J., 2009. Recovery of high purity precious metals from printed circuit boards. J. Hazard. Mater. 164, 1152-1158. https://doi.org/10.1016/j.jhazmat.2008.09.043

Petter, P.M.H., Veit, H.M., Bernardes, A.M., 2014. Evaluation of gold and silver leaching from printed circuit board of cellphones. Waste Manag. 34, 475-482. https://doi.org/10.1016/j.wasman.2013.10.032

Poirot, R., Bourgeois, D., Meyer, D., 2014. Palladium Extraction by a Malonamide Derivative (DMDOHEMA) from Nitrate Media: Extraction Behavior and Third Phase Characterization. Solvent Extr. Ion Exch. 32, 529-542. https://doi.org/10.1080/07366299.2014.908587

Poirot, R., Le Goff, X., Diat, O., Bourgeois, D., Meyer, D., 2016. Metal Recognition Driven by Weak Interactions: A Case Study in Solvent Extraction. ChemPhysChem 17, 2112-2117. https://doi.org/10.1002/cphc.201600305

Ponou, J., Wang, L.P., Dodbiba, G., Fujita, T., 2018. Separation of palladium and silver from semiconductor solid waste by means of liquid-liquid-powder extraction using dodecyl amine acetate as a surfactant collector. Sep. Purif. Technol. 191, 86-93. https://doi.org/10.1016/j.seppur.2017.09.009

Prabaharan, G., Barik, S.P., Kumar, B., 2016. A hydrometallurgical process for recovering total metal values from waste monolithic ceramic capacitors. Waste Manag. 52, 302-308. https://doi.org/10.1016/j.wasman.2016.04.010

Serrano-Purroy, D., Baron, P., Christiansen, B., Malmbeck, R., Sorel, C., Glatz, J.-P., 2005. Recovery of minor actinides from HLLW using the DIAMEX process. Radiochim. Acta 93. https://doi.org/10.1524/ract.93.6.351.65642

Sun, Z., Xiao, Y., Agterhuis, H., Sietsma, J., Yang, Y., 2016. Recycling of metals from urban mines - a strategic evaluation. J. Clean. Prod. 112, 2977-2987. https://doi.org/10.1016/j.jclepro.2015.10.116

Sverdrup, H.U., Ragnarsdottir, K.V., 2016. A system dynamics model for platinum group metal supply, market price, depletion of extractable amounts, ore grade, recycling and stocks-in- 
use. Resour. Conserv. Recycl. 130-152. https://doi.org/10.1016/j.resconrec.2016.07.011

Sypula, M., Wilden, A., Schreinemachers, C., Malmbeck, R., Geist, A., Taylor, R., Modolo, G., 2012. Use of Polyaminocarboxylic Acids as Hydrophilic Masking Agents for Fission Products in Actinide Partitioning Processes. Solvent Extr. Ion Exch. 30, 748-764. https://doi.org/10.1080/07366299.2012.700591

Wang, S.F., Dougherty, J.P., Huebner, W., Pepin, J.G., 1994. Silver-Palladium Thick-Film Conductors. J. Am. Ceram. Soc. 77, 3051-3072. https://doi.org/10.1111/j.11512916.1994.tb04549.x

Wang, Y., Baker, L.A., Brindle, I.D., 2016. Determination of gold and silver in geological samples by focused infrared digestion: A re-investigation of aqua regia digestion. Talanta 148, 419426. https://doi.org/10.1016/j.talanta.2015.11.019

Xiu, F.-R., Qi, Y., Zhang, F.-S., 2015. Leaching of Au, Ag, and Pd from waste printed circuit boards of mobile phone by iodide lixiviant after supercritical water pre-treatment. Waste Manag. 41, 134-141. https://doi.org/10.1016/j.wasman.2015.02.020

Xu, G., Yano, J., Sakai, S., 2019. Recycling Potentials of Precious Metals from End-of-Life Vehicle Parts by Selective Dismantling. Environ. Sci. Technol. 53, 733-742. https://doi.org/10.1021/acs.est.8b04273

Yang, C., Li, J., Tan, Q., Liu, L., Dong, Q., 2017. Green Process of Metal Recycling: Coprocessing Waste Printed Circuit Boards and Spent Tin Stripping Solution. ACS Sustain. Chem. Eng. 5, 3524-3534. https://doi.org/10.1021/acssuschemeng.7b00245

Yang, H., Liu, J., Yang, J., 2011. Leaching copper from shredded particles of waste printed circuit boards. J. Hazard. Mater. 187, 393-400. https://doi.org/10.1016/j.jhazmat.2011.01.051

Yazici, E.Y., Deveci, H., 2013. Extraction of metals from waste printed circuit boards (WPCBs) in $\mathrm{H} 2 \mathrm{SO} 4-\mathrm{CuSO} 4-\mathrm{NaCl} \quad$ solutions. Hydrometallurgy $\quad 139, \quad 30-38$. https://doi.org/10.1016/j.hydromet.2013.06.018

Yoo, K., Lee, J., Lee, K., Kim, B., Kim, M., Kim, S., Pandey, B.D., 2012. Recovery of Sn, Ag and $\mathrm{Cu}$ from Waste Pb-Free Solder Using Nitric Acid Leaching. Mater. Trans. 53, 2175-2180. https://doi.org/10.2320/matertrans.M2012268

Zhang, X., Guan, J., Guo, Y., Yan, X., Yuan, H., Xu, J., Guo, J., Zhou, Y., Su, R., Guo, Z., 2015. Selective Desoldering Separation of Tin-Lead Alloy for Dismantling of Electronic Components from Printed Circuit Boards. ACS Sustain. Chem. Eng. 3, 1696-1700. https://doi.org/10.1021/acssuschemeng.5b00136

Zhang, Z., Zhang, F.-S., 2014. Selective recovery of palladium from waste printed circuit boards by a novel non-acid process. J. Hazard. Mater. 279, 46-51. https://doi.org/10.1016/j.jhazmat.2014.06.045 